\title{
TAMANHO NÃO É DOCUMENTO: FORÇA DO ARMAMENTO, E NÃO TAMANHO CORPORAL, PREDIZ DOMINÂNCIA INTERESPECÍFICA EM INTERAÇÕES AGRESSIVAS ENTRE DOIS DECÁPODOS DE ÁGUA DOCE (CRUSTACEA)
}

\author{
Dalosto, M.M. ${ }^{1,}$; Palaoro, A.V. ${ }^{1,2}$; Lopes, F.B. ${ }^{1}$ \& Santos, S. ${ }^{1}$ \\ ${ }^{1}$ Núcleo de Estudo em Biodiversidade Aquática, Programa de Pós-Graduação em Biodiversidade Animal, Centro de \\ Ciências Naturais e Exatas, Universidade Federal de Santa Maria. \\ ${ }^{2}$ LAGE, Departamento de Ecologia, Universidade de São Paulo. \\ *Autor correspondente: marcelo.dalosto@gmail.com
}

\begin{abstract}
Interações agressivas entre espécies diferentes são comuns na natureza, mas são difíceis de serem estudadas. O plano corporal de cada espécie pode variar consideravelmente, como, por exemplo, confrontos entre caranguejos e camarões, o que dificulta testar quais variáveis influenciam a dominância interespecífica. dado que confrontos de crustáceos geralmente envolvem agarrar o oponente com os quelípodos, propomos uma que abordagem funcional baseada em força conseguiria prever a dominância interespecífica melhor que abordagens morfológicas. Nossas hipóteses são: (1) a força do quelípodo será um melhor preditor do resultado desses confrontos do que medidas de tamanho corporal; e (2) confrontos nos quais os indivíduos são mais similares serão mais intensos. Nós utilizamos como modelos os decápodos Aegla longirostri Bond-Buckup \& Buckup, 1994 e Parastacus brasiliensis (von Martens, 1869) que ocorrem em simpatria, possuem nichos similares e frequentemente se confrontam. Nós realizamos confrontos de pares interespecíficos $(n=23$ pares) de animais de tamanhos aleatórios, e medimos as diferenças entre os animais com relação à tamanho, peso e força do armamento, utilizando essas diferenças como preditoras dos parâmetros comportamentais observados. Os parâmetros foram testados através de modelos lineares generalizados (GLMs) com uma estrutura de erro binomial (vencedor do confronto), de Poisson (número de embates) ou gaussiana (tempo de latência, tempo até nível agressivo mais alto, duração do primeiro embate, duração média dos embates, tempo total de confronto). Nossa primeira hipótese foi corroborada: a força do quelípodo foi positivamente correlacionada com o vencedor, enquanto o tamanho corporal não (GLM; $\left.\chi^{2} 1,19=4.732 ; p=0.029\right)$. Contudo, confrontos de indivíduos de forças similares não foram mais agressivos, e os confrontos se intensificaram mais rapidamente à medida que a disparidade de tamanho aumentava, contrariando nossa segunda hipótese (GLM; $\left.\chi^{21} 1,20=0.547 ; p=0.034\right)$. Nossos resultados sustentam a ideia de que a força do armamento é um melhor preditor de dominância interespecífica, sendo um fator interessante para ser incluso em desenhos experimentais. Nós também corroboramos a hipótese de que os eglídeos possuem alguma vantagem competitiva sobre os lagostins, sendo os mais prováveis vencedores quando os animais são equivalentes na força de seu armamento.
\end{abstract}

Palavras-chave: Aegla, agressão interespeífica, competição, delineamento experimental, Parastacus. 